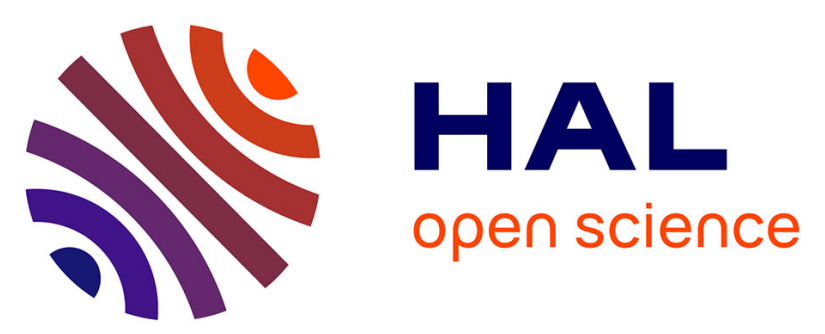

\title{
Simulation of aerosols and gas-phase species over Europe with the POLYPHEMUS system: Part I - Model-to-data comparison for 2001
}

Karine Sartelet, Edouard Debry, K. Fahey, Marilyne Tombette, Yelva Roustan, Bruno Sportisse

\section{To cite this version:}

Karine Sartelet, Edouard Debry, K. Fahey, Marilyne Tombette, Yelva Roustan, et al.. Simulation of aerosols and gas-phase species over Europe with the POLYPHEMUS system: Part I - Model-to-data comparison for 2001. Atmospheric Environment, 2007, 41 (29), pp.6116-6131. 10.1016/j.atmosenv.2007.04.024 . inria-00633774

\section{HAL Id: inria-00633774 \\ https://hal.inria.fr/inria-00633774}

Submitted on 8 Feb 2018

HAL is a multi-disciplinary open access archive for the deposit and dissemination of scientific research documents, whether they are published or not. The documents may come from teaching and research institutions in France or abroad, or from public or private research centers.
L'archive ouverte pluridisciplinaire HAL, est destinée au dépôt et à la diffusion de documents scientifiques de niveau recherche, publiés ou non, émanant des établissements d'enseignement et de recherche français ou étrangers, des laboratoires publics ou privés. 


\title{
Simulation of aerosols and gas-phase species over Europe with the Polyphemus system: Part I-Model-to-data comparison for 2001
}

\author{
K.N. Sartelet*, E. Debry, K. Fahey, Y. Roustan, M. Tombette, B. Sportisse \\ CEREA, 6-8 avenue Blaise Pascal, Cité Descartes Champs-sur-Marne, 77455 Marne la Vallée Cedex 2, France
}

Received 6 September 2006; received in revised form 30 March 2007; accepted 11 April 2007

\begin{abstract}
This paper aims at presenting a validation of multi-pollutants over Europe with a focus on aerosols. ChemistryTransport Models are now used for forecast and emission reduction studies not only for gas-phase species but also for aerosols. Comprehensive model-to-data comparisons are therefore required. We present in this paper a preliminary validation study of the Polyphemus system applied over Europe for 2001. The aerosol model is the SIze REsolved Aerosol Model (SIREAM). It is a sectional model that describes the temporal evolution of the size/composition distribution of atmospheric particles containing a mix of black carbon, mineral dust, inorganic species, and primary and secondary organics. In addition to a brief model description, we present an overview of the model validation. A comprehensive set of model-to-data statistics is computed with observational data extracted from three European databases (the EMEP, AirBase and BDQA databases). Model performance criteria are verified for ozone and particulate matter (PM) and its inorganic components. Comparisons of correlations and root mean square errors with those generated by other models run over Europe for 2001 indicate a good performance of the PolyPHEmus system. Modifications of the system configuration and parameterizations may have a significant impact on error statistics, which may question the robustness of such models. Because large differences exist between databases, the robustness of model-to-data error statistics is also investigated.

(C) 2007 Elsevier Ltd. All rights reserved.
\end{abstract}

Keywords: Aerosol; Monitoring network; Chemistry-Transport Model; Model performance criteria

\section{Introduction}

Aerosol modeling is a field of growing interest for many reasons. Particles, especially fine particles, have been implicated in adverse effects on human health (e.g. Pope et al., 1995; Hoek et al., 2002). Atmospheric particles also affect the manner in which radiation passes through the atmosphere

*Corresponding author.

E-mail address: sartelet@cerea.enpc.fr (K.N. Sartelet).
(Haywood and Boucher, 2000) and represent an uncertain component of the atmospheric response to the increasing emissions of greenhouse gases. The first motivation for better understanding the behavior of atmospheric aerosol is then related to air quality, while the second one is related to climate change.

Many regulations for air quality now focus on particulate matter (PM) mass. This is the case with the EPA standards in the United States and also the case in Europe with the Clean Air For Europe 
(CAFE) procedure. Models are powerful tools to assess the effects of proposed emission reductions on particulate concentrations. In order to have confidence in these models, however, it is necessary to validate them with observational data. In the past decade, numerous studies have been performed to assess the capacity of Chemistry-Transport Models to simulate the composition and spatio-temporal distribution of aerosols at regional and urban scales (e.g. Cousin et al., 2005; Hodzic et al., 2006a; Zhang et al., 2006; Vautard et al., 2007). Several models are now available in Europe and have been validated and compared for gaseous species and sometimes aerosols. Among many others, one can cite EMEP (Simpson et al., 2003), LOTOS-EUROS (Schaap et al., 2004a, b), EURAD (Ackermann et al., 1995), DREAM (Brandt, 1998) and CHIMERE (Schmidt et al., 2001). They have been tested against aerosol chemical and optical (e.g. de Meij et al., 2006; Hodzic et al., 2006b) measurements provided by ground networks and satellite data. Several models were evaluated for a full year over Europe. For example, Schaap et al. (2004a, b) simulated the aerosol distribution over Europe for the year 1995, and Bessagnet et al. (2004) for the year 2001, but they did not take into account sea salt and natural dust emissions. van Loon et al. (2004) intercompared seven models over Europe for the years 1999 and 2001 for ozone, $\mathrm{NO}_{x}$, inorganic aerosols and their precursors. A specific exercise (the EURODELTA program) has also been carried out in order to analyze the responses of different models to emission changes. In this framework, the models are intercompared and compared to ozone measurements for the year 2001 (van Loon et al., 2007).

Polyphemus is a modeling system that has been developed for forecasts and assessment of emission reduction strategies over Europe. Its novelty is that it is not an "all-in-one" model: it has been designed as a modular system able to host different model configurations and is thus well-suited for ensemble modeling (Mallet and Sportisse, 2006a). It is the basis of the future forecast system of the French Institute for Nuclear Safety (Quélo et al., 2007) and has been involved in operational testing for photochemistry forecasts on the French Prév'air platform since July 2006 (www.prevair.org). A key focus of Polyphemus is devoted to the model sensitivity with respect to emissions (Mallet and Sportisse, 2005). Many topics related to uncertainties have already been investigated with Polyphemus (Mallet and Sportisse, 2006b). Polyphemus has already been applied to aerosol modeling, through its ChemistryTransport Model (Polair3D), in the MICS (Model Intercomparison Study, Phase II) Asia exercise (Sartelet et al., 2007). Previous European studies with Polyphemus have focused on gas-phase chemistry over summer, and this paper is the logical extension to a full year validation with aerosol modeling. In the framework of studying uncertainties of gas-phase and aerosol species related to modifications of the system configuration and parameterizations over a full year, the focus of this paper is a preliminary validation with a model-todata comparison for the year 2001 over Europe. This comparison is done using different databases to quantify the robustness of model-to-data error statistics.

This paper is structured as follows. A brief description of the Polyphemus system and of the aerosol model SIREAM (SIze REsolved Aerosol Model) are given in the first section. The model validation exercise is presented in Section 1. The Polyphemus system is used for simulating aerosol over Europe for the year 2001. Error statistics for model-to-data comparisons are computed on the basis of observational data given by three different databases (EMEP, AirBase and BDQA). The focus is on inorganic species and $\mathrm{PM}_{10}$ due both to model uncertainties and the lack of measured data for secondary organic aerosol. The results are discussed in the third section. The paper ends with a conclusion and the presentation of future work. A companion paper (Part II) is devoted to a sensitivity analysis.

\section{Model description}

\subsection{The Polyphemus system}

Polyphemus and its Chemistry-Transport Model POLAIR3D have already been used for many applications, e.g. sensitivity analysis of ozone with respect to emissions (Mallet and Sportisse, 2005), modeling of mercury and heavy metals at continental scale (Roustan and Bocquet, 2006). The Polyphemus platform is made of four distinct components:

- Physical parameterizations and preprocessing of input fields (meteorological fields, boundary conditions and emissions) are performed within the AtmoData library.

- Drivers have been defined in order to handle high-level use of the models, which can be viewed 
as black boxes, e.g. a driver for Monte Carlo simulations, a driver for ensemble forecast.

- Models (for instance the Chemistry-Transport Model Polair3D) constitute the third level of the system. Short-range models (puff and gaussian models) and another CTM, Castor (based on Chimere, Schmidt et al., 2001) are also available.

- The last level is composed of postprocessing tools, especially the Python module AтмoPy. This library (which does not depend on the previous components) performs model-to-data comparisons.

Polyphemus is developed with a GNU/GPL license and the source code is downloadable from the web site http://www.enpc.fr/cerea/polyphemus.

\subsection{Gas-phase chemistry}

The chemical mechanism chosen for the simulation is RACM (Stockwell et al., 1997). Photolysis rates are computed off-line, as done in the photolysis rate preprocessor JPROC of CMAQ (Roselle et al., 1999).

\subsection{The SIze REsolved Aerosol Model (SIREAM)}

Two aerosol models are hosted by Polyphemus: MAM (a Modal Aerosol Model, Sartelet et al., 2005) and SIREAM (a SIze REsolved Aerosol Model, Debry et al., 2007). Both models rely on the same parameterizations hosted by the ATmoDATA library (Sportisse et al., 2006). SIREAM is used for this study.

\subsection{Deposition and wet scavenging}

\subsubsection{Gases}

The dry deposition velocities are preprocessed by using the parameterization of Zhang et al. (2003). As in Simpson et al. (2003), the surface resistance is modeled following Wesely (1989) for sub-zero temperatures, and the surface resistance of $\mathrm{HNO}_{3}$ is assumed to be zero for positive temperatures. Below-cloud scavenging (washout) is parameterized following Sportisse and Dubois (2002). During below-cloud scavenging, equilibrium concentrations of soluble gaseous species can be significantly affected by the ion dissociation during dissolution in water. To take this ionization process into account, effective Henry coefficients are computed given the raindrop $\mathrm{pH}$ for the following species: $\mathrm{SO}_{2}, \mathrm{NH}_{3}, \mathrm{HNO}_{3}, \mathrm{HNO}_{2}$ and $\mathrm{HCl}$.

\subsubsection{Aerosols}

Dry deposition is parameterized with a resistance approach, following Zhang et al. (2001). Belowcloud scavenging is parameterized with the washout coefficient $\Lambda\left(d_{\mathrm{p}}\right)=\frac{3}{2} E\left(D_{\mathrm{r}}, d_{\mathrm{p}}\right) p_{0} / D_{\mathrm{r}}$, with $p_{0}$ the rain intensity in ISU $\left(\mathrm{m} \mathrm{s}^{-1}\right), d_{\mathrm{p}}$ the particle diameter, $D_{\mathrm{r}}$ the raindrop diameter and $E$ the collision efficiency. The representative diameter for the rain is given as a function of $p_{0}$ following Loosmore and Cederwall (2004). The raindrop velocity is computed as a function of the raindrop diameter following Loosmore and Cederwall (2004).

In-cloud scavenging (rainout) is parameterized following Roselle and Binkowski (1999).

In the case of a fog, diagnosed as a cloud whose first level is at ground, the fog settling velocity is parameterized following Pandis et al. (1990).

\section{Model setup and comparison methodology}

\subsection{Model simulation characteristics}

\subsubsection{Domain}

Simulations are performed over Europe. The coordinates of the southwestern-most point are $\left(10.75^{\circ} \mathrm{W}, 34.75^{\circ} \mathrm{N}\right)$ in longitude/latitude. The domain of simulation covers an area of $33.5^{\circ} \times 23^{\circ}$ with a step of $0.5^{\circ}$ along both longitude and latitude. Five vertical levels are considered from the ground to $3000 \mathrm{~m}$. The heights of the cell interfaces are $0,50,600,1200,2000$ and $3000 \mathrm{~m}$.

\subsubsection{Meteorological data}

Meteorological data are provided by ECMWF (31 vertical levels with a horizontal resolution of $0.36^{\circ} \times 0.36^{\circ}$ every $3 \mathrm{~h}$ ). Vertical diffusion is computed using the Troen and Mahrt parameterization (Troen and Mahrt, 1986) within the boundary layer, and using the Louis parameterization (Louis, 1979) above it. For land use coverage the USGS (United States Geological Survey) land cover map (24 categories) is used.

\subsubsection{Boundary conditions}

For boundary conditions, daily means are extracted from outputs of the global ChemistryTransport Model Mozart 2 run over a typical year for gas, and from outputs of the Goddard Chemistry Aerosol Radiation and Transport (GOCART Chin 
et al., 2000) model for the year 2001 for sulfate, dust, black carbon and organic carbon.

Forty percent of organic carbon is assumed to be primary aerosol. The remaining $60 \%$ is equally distributed amongst the eight organic species of SIREAM on a molar basis. Boundary conditions for sea salt are also provided by GOCART, but they are not used because local emissions of sea salt are taken into account in the system.

As recommended in Vautard et al. (2005), boundary conditions of dust are drastically lowered (here divided by 4), because high dust events are very sporadic and the use of mean values may lead to overestimation of dust concentrations.

Boundary conditions for ammonium are deduced from the sulfate boundary conditions by assuming electro-neutrality of sulfate and ammonium. GOCART provides only total concentrations of sulfate and carbon. Therefore they need to be redistributed amongst the five sections of the aerosol module. The GOCART concentrations are assumed to follow a trimodal lognormal distribution of parameters $\left(N_{1}=8128 \times 10^{6} \mathrm{~m}^{3}, d_{1}=0.014 \mu \mathrm{m}, \sigma_{1}=1.92\right)$ for the first mod, $\left(N_{2}=4633 \times 10^{6} \mathrm{~m}^{3}, d_{2}=0.045 \mu \mathrm{m}\right.$, $\left.\sigma_{2}=1.87\right)$ for the second mode and $\left(N_{3}=1235 \times\right.$ $\left.10^{6} \mathrm{~m}^{3}, d_{3}=0.162 \mu \mathrm{m}, \sigma_{3}=1.71\right)$ for the third mode. $N_{i}$ is the number of particles in the mode, $d_{i}$ the geometric mean diameter and $\sigma_{i}$ the geometric standard deviation (Putaud et al., 2003). Integrating this lognormal distribution over each section gives the percentage of the mass to be allocated to each section. For dust concentrations, GOCART provides concentrations for five bins ranging between 0.1 and $10 \mu \mathrm{m}$. For each GOCART bin, the percentage of the mass to be allocated to each section is computed similarly to sulfate and carbon. The trimodal lognormal distribution is integrated over each section.

\subsubsection{Emission}

2.1.4.1. Gases. Anthropogenic emissions are generated with the EMEP expert inventory for 2001. A typical time distribution of emissions, given for each month, day and hour (GENEMIS, 1994) is applied to each emission sector or SNAP (Selected Nomenclature for Air Pollution) category. Except for the SNAP 10 (agriculture), monthly emission and hourly emission factors are applied following Schaap (2003, pp. 4-46). The inventory species are disaggregated into real species using speciation coefficients (Passant, 2002). $\mathrm{NO}_{x}$ emissions are split into $90 \%$ of $\mathrm{NO}$ (in mass), $9.2 \%$ of $\mathrm{NO}_{2}$ and $0.8 \%$ of $\mathrm{HONO} . \mathrm{SO}_{x}$ emissions are split into $95 \%$ of $\mathrm{SO}_{2}$ and $5 \%$ of $\mathrm{H}_{2} \mathrm{SO}_{4}$ (in molar concentrations) following Simpson et al. (2003). The aggregation into model species (for RACM) is done following Middleton et al. (1990). Because emissions are assumed to be instantaneously mixed throughout the first mixing layer, and because gradients from surfacic $\mathrm{NH}_{3}$ emission maybe very strong, the deposition of $\mathrm{NH}_{3}$ close to sources is underestimated. To account for this effect, $25 \%$ of $\mathrm{NH}_{3}$ emissions are deposited locally (Tsyro, 2001; Loubet et al., 2003). Biogenic emissions are computed as in Simpson et al. (1999). Two-third of terpene emissions are allocated to $\alpha$-pinene and one-third to limonene (Johnson et al., 2006).

2.1.4.2. Aerosols. Primary particle emissions are usually given in total mass. For example, the EMEP European emission inventory provides yearly quantities for $\mathrm{PM}_{2.5}$ and $\mathrm{PM}_{10}$ (particles with diameters less than 2.5 and $10 \mu \mathrm{m}$ respectively) or PM coarse (particles with diameters between 2.5 and $10 \mu \mathrm{m}$ ). These brute data have to be temporally, chemically, and granulometrically speciated. We follow the recommendations of Simpson et al. (2003). The PM coarse fraction is attributed to mineral dust. The $\mathrm{PM}_{2.5}$ fraction is first chemically speciated into three species (mineral dust, MD, primary organics aerosols, POA, and black carbon, BC) by emission source category or SNAP code. These three species contribute to about $35 \%$ for dust, $45 \%$ for POA and $20 \%$ for $\mathrm{BC}$ of the total $\mathrm{PM}_{2.5}$ mass. They are then distributed into two modes (the Aitken and the accumulation modes). The redistribution of the quantities in the model bins is based on the assumption that each bin belongs to one mode. The emissions of a mode are then equally partitioned amongst the bins that are included in this mode. Sensitivity tests (not reported here) show that the distribution of emissions does not have a great influence compared to other sources of uncertainties.

Sea-salt emissions are parameterized following Monahan et al. (1986), which models the generation of sea salt by the evaporation of sea spray produced by bursting bubbles during whitecap formations due to surface wind. This parameterization is valid at $80 \%$ relative humidity. To generalize it, the formula is expressed in terms of dry radius, which is assumed to be approximatively half the radius at $80 \%$ humidity (Gerber, 1985). The emitted mass of sea salt is assumed to be made of $55.025 \%$ of chloride, $39.33 \%$ of sodium and $7.68 \%$ of sulfate (Seinfeld 
and Pandis, 1998). Although based on the composition of sea water (Seinfeld and Pandis, 1998), sea salt is made of only $30.61 \%$ of sodium, the percentage of sodium is taken as $39.33 \%$ here. In the real atmosphere, cations such as magnesium and calcium would also contribute to the composition of sea salt. Because these cations are not taken into account in Polyphemus, the percentage of sodium is artificially increased to keep the emitted sea-salt particles electro-neutral.

\subsection{Error statistics}

The simulation is run over the year 2001, and the evaluation is made for both gases and aerosols. Hourly and peak statistics are computed for $\mathrm{O}_{3}$. Hourly statistics are computed for $\mathrm{NO}_{2}$, while daily statistics are computed for $\mathrm{SO}_{2}, \mathrm{NH}_{3}, \mathrm{HNO}_{3}$ and $\mathrm{PM}\left(\mathrm{PM}_{10}\right.$, sulfate, nitrate, ammonium, sodium and chloride).

\subsubsection{Measured data}

The model results are compared to observational data provided by three databases:

- the EMEP database, available on the EMEP Chemical Co-ordinating Centre (EMEP/CCC) web site at http://www.emep.int;

- the AirBase database, available on the European Environment Agency (EEA) web site at http:// air-climate.eionet.europa.eu/databases/airbase;

- The BDQA database ("Base de Données Qualité de l'Air": the French Data Basis for Air Quality that covers France), information is available at http://www.atmonet.org/.

The location of the stations is given in Fig. 1 for each of the three databases.

The measurement sites of the EMEP network are assumed to be representative of the regional background concentrations (Torseth and Hov, 2003). The AirBase database contains observational data from the European Air Quality monitoring network (EuroAirnet). For our comparisons only the stations labeled as "background" representative have been used. However, it should be kept in mind that "background" does not have exactly the same meaning between AirBase and EMEP. In AirBase, although traffic and industrial stations have been excluded, stations labeled as background may be representative of urban or suburban background stations. The same kind of filter has been applied to data from the BDQA, in which "rural" and "suburban" stations have been retained.

Measurement data used in this paper are given on a daily average basis except for ozone, for which hourly averages are available. Since AirBase contains observational data from several European networks, some time series measurements may be provided by both AirBase and BDQA or EMEP databases.

There are many uncertainties in the observational data. First, some sites may be not representative of background values (not far enough from important emissions). Second, some sites may be strongly impacted by local conditions (for instance orography). Third, the observational error may be large due to artifacts in the measurement methods (we refer for instance to Schaap et al., 2004a for a deeper understanding; a key process is evaporation of the samples, for example).

The aerosol water content is not taken into account in the model-to-data comparisons. Moreover, although the aerodynamic diameter is used for $\mathrm{PM}_{10}$ and $\mathrm{PM}_{2.5}$ in measurements, the Stokes diameter is used in the modeling and for the comparison to measurements. The discrepancy in the results is not significant as compared to other uncertainties.
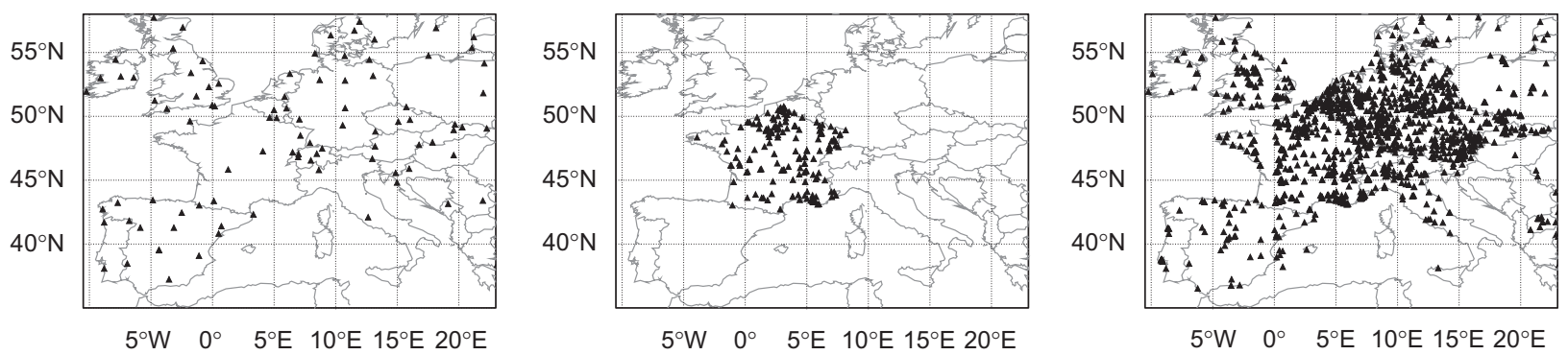

Fig. 1. Locations of the stations for the EMEP (left panel), the BDQA (middle panel) and the AirBase (right panel) databases. 


\subsubsection{Statistical indicators}

The key statistical indicators are the correlation coefficient $(\%)$ and the root mean square error (RMSE) $\left(\mu \mathrm{g} \mathrm{m}^{-3}\right)$ (given in Appendix). The smaller the RMSE and the larger the correlation, the better the model fits the observations. The US EPA (EPA, 1991; Russell and Dennis, 2000) recommends using the mean normalized bias error (MNBE) and the mean normalized gross error (MNGE) with an observation-based minimum threshold of 40-60 ppb (about $80-120 \mu \mathrm{g} \mathrm{m}^{-3}$ ) to evaluate hourly ozone. The suggested performance criterion is MNBE $\leqslant \pm 15 \%$ and MNGE $\leqslant 30 \%$. When computing statistics for ozone in this paper, a threshold of $80 \mu \mathrm{g} \mathrm{m}^{-3}$ is chosen. Bias indicates whether the model tends to under or overpredict the observations, and error and RMSE indicate how large the deviation is. According to Boylan and Russell (2006), the MNBE and MNGE may not be appropriate to evaluate PM. They suggested using instead the mean fractional bias MFB (\%) and the mean fractional error MFE (\%). They propose that a model performance goal is met when both the MFE and the MBE are less than or equal to $+50 \%$ and $\pm 30 \%$, respectively, and a model performance criterion is met when both MFE $\leqslant+75 \%$ and MFB $\leqslant \pm 60 \%$.

\section{Result analysis}

\subsection{Diurnal cycle of ozone}

Fig. 2 shows the yearly mean diurnal cycle of hourly ozone averaged over all BDQA stations and EMEP stations. The model captures very well the diurnal variations of ozone. The peak of ozone in the afternoon is well simulated both in terms of timing and amplitude. At the EMEP stations, the peak is overestimated by $2 \mu \mathrm{g} \mathrm{m}^{-3}$, while it is underestimated by less than $1 \mu \mathrm{g} \mathrm{m}^{-3}$ at the BDQA stations. A spread in the amplitude of the ozone peak, as large as $20 \mu \mathrm{g} \mathrm{m}^{-3}$, is observed by van Loon et al. (2007) which compare seven models for the year 2001. As in van Loon et al. (2007), the spread is larger during night time. At the EMEP stations, the low ozone concentrations are underestimated by $8 \mu \mathrm{g} \mathrm{m}^{-3}$.

\subsection{Spatial distribution}

The spatial distribution of pollutants over Europe is shown in Fig. 3 for $\mathrm{PM}_{10}, \mathrm{PM}_{2.5}$, dust, sea salt, nitrate and ammonium. The spatial distribution of $\mathrm{PM}_{2.5}$ shows similar patterns to the distribution computed by Bessagnet et al. (2004) for the year 1999, with high concentrations over northern Italy, the north east of Spain, The Netherlands, Germany and eastern European countries. The spatial distribution of $\mathrm{PM}_{10}$ differs from that of Bessagnet et al. (2004), which did not include sea salt and dust. As shown in Fig. 3, the high $\mathrm{PM}_{10}$ concentrations observed in the south part of Europe are made mostly of Saharan dust, while the high concentrations in the west part of the domain are mostly due to sea salt.

Fig. 4 shows the simulated gas ratio (GR) (Park et al., 2004)

$\mathrm{GR}=\frac{\left[\mathrm{NH}_{3}^{T}\right]-2\left[\mathrm{SO}_{4}^{2-}\right]}{\left[\mathrm{HNO}_{3}^{T}\right]}$,

where concentrations are in molar units, $\left[\mathrm{NH}_{3}^{T}\right]$ is the sum of ammonium and ammonia, $\left[\mathrm{HNO}_{3}^{T}\right]$ is the sum of aerosol nitrate and nitric acid and $\left[\mathrm{SO}_{4}^{2-}\right]$ is
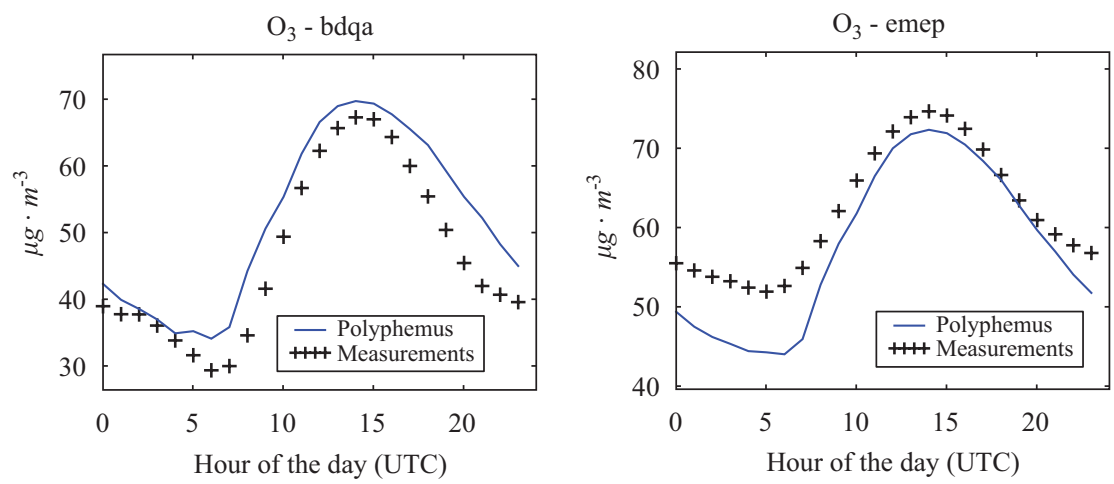

Fig. 2. Yearly mean diurnal cycle of hourly ozone averaged over all BDQA stations (left panel) and EMEP stations (right panel). 

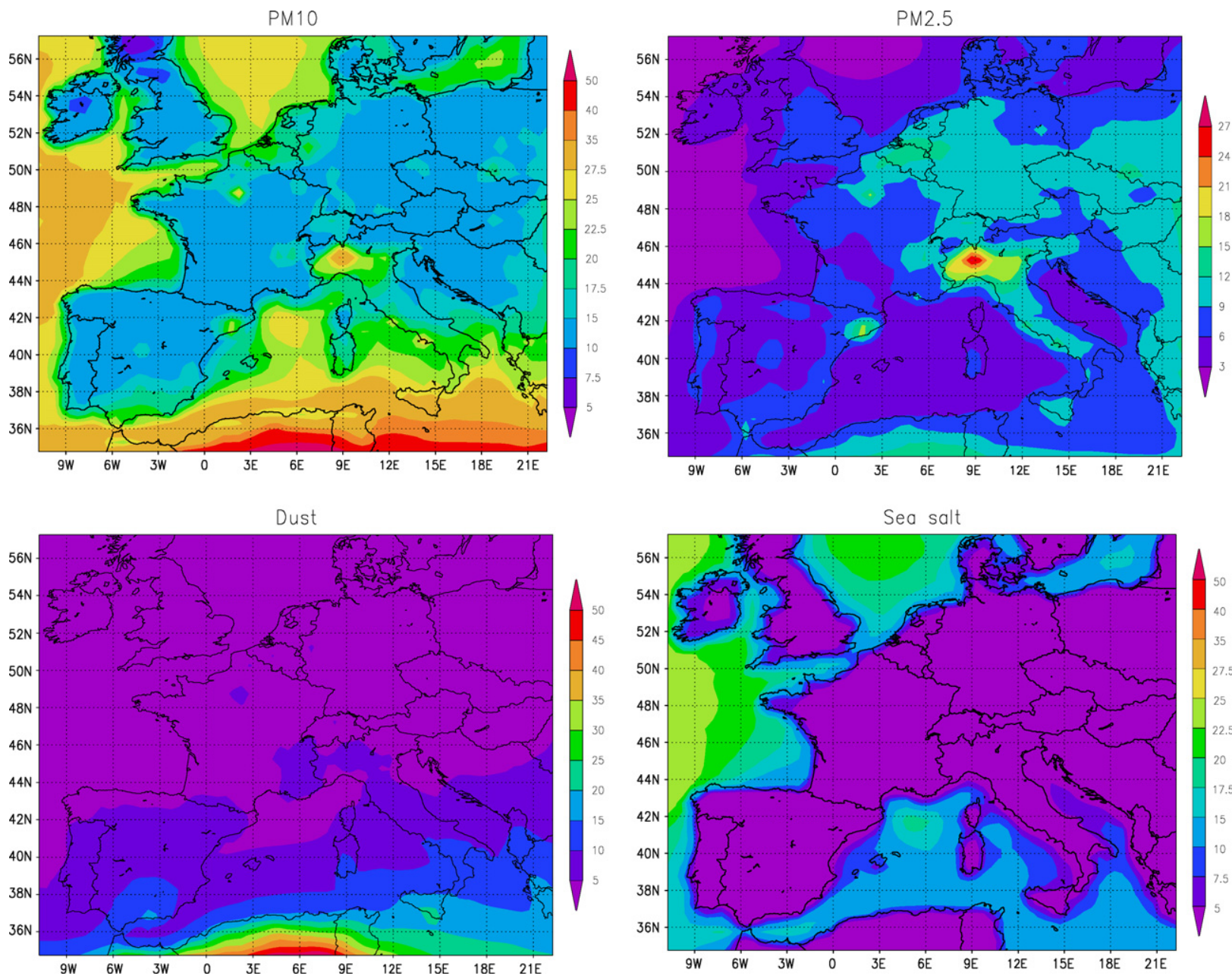

Fig. 3. Yearly mean concentrations (in $\mu \mathrm{g} \mathrm{m}^{-3}$ ) of PM components in 2001.

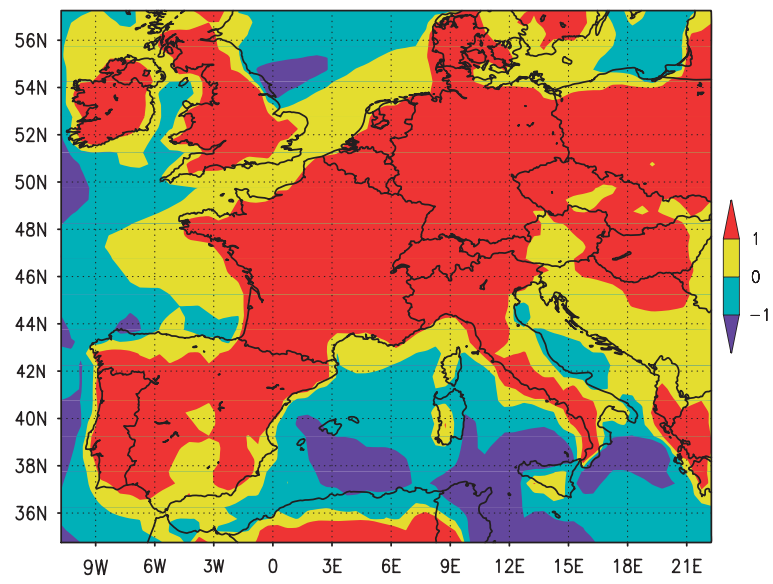

Fig. 4. Mean simulated gas ratio in 2001.

the sulfate concentration. As shown by Park et al. (2004) over the United States, negative GR values, which indicate an acidic sulfate aerosol, are limited to the oceans. Although in Park et al. (2004) over the United States, the supply of ammonia limits the formation of ammonium nitrate $(0<\mathrm{GR}<1)$, in Europe and especially in western Europe, the ammonium nitrate formation is limited by the formation of nitric acid (GR $>1)$.

\subsection{Yearly averaged statistics}

Statistics obtained with Polyphemus over Europe in 2001 are shown for the three monitoring networks in Tables 1-3.

Statistics strongly vary depending on the observational data network used. For example, $\mathrm{NO}_{2}$ and $\mathrm{SO}_{2}$ observed values are, respectively, 2 and 3 times higher with AirBase or BDQA stations than with EMEP stations. These differences stress the importance of the filtering of the stations used for the comparisons. Although urban stations are filtered 
out of all databases, stations that are not truly background stations, such as suburban stations, are not filtered out in some databases.

An intercomparison of seven models over Europe for 2001 is presented in van Loon et al. (2004), hereafter referred to as TNO-04. The data used in the report differ from one model to another, e.g. for meteorological data, boundary conditions, emissions, etc. However, it provides a good basis for evaluating the reliability of the results obtained with PolyPHEMUS over Europe for the year 2001. Measurements from both the EMEP and the AirBase databases were used to compute the statistics.

\subsubsection{Model performance goal and criterion}

The EPA criteria for ozone and ozone peaks are met. Although MNBE goes to values as high as the

Table 1

Statistics obtained with Polyphemus over Europe in 2001 for ozone: number of stations used to compute the statistics, observed mean $\left(\mu \mathrm{g} \mathrm{m}^{-3}\right)$, modeled mean $\left(\mu \mathrm{g} \mathrm{m}^{-3}\right)$, RMSE $\left(\mu \mathrm{g} \mathrm{m}^{-3}\right)$, correlation $(\%), \operatorname{MFB}(\%), \operatorname{MFE}(\%), \operatorname{MNBE}(\%)$ and MNGE (\%)

\begin{tabular}{lccccccc}
\hline & \multicolumn{2}{l}{$\mathrm{O}_{3}$ hourly } & \multicolumn{2}{l}{$\mathrm{O}_{3}$ peak } \\
\cline { 2 - 4 } \cline { 7 - 8 } & EMEP & AirBase & BDQA & & EMEP & AirBase & BDQA \\
\hline Stations & 96 & 993 & 135 & & 96 & 996 & 139 \\
Obs. mean & 63.2 & 49.9 & 53.1 & & 80.2 & 73.7 & 77.4 \\
Mod. mean & 57.0 & 53.2 & 55.5 & & 73.5 & 72.5 & 73.7 \\
RMSE & 24.3 & 26.0 & 25.2 & & 21.4 & 23.5 & 23.2 \\
Corr. & 63.9 & 67.5 & 69.1 & & 72.1 & 76.5 & 77.4 \\
MFB & 40 & 12 & 12 & & -7 & 5 & 1 \\
MFE & -10 & 55 & 50 & & 24 & 31 & 27 \\
MNBE & -18 & -16 & -16 & & -14 & -14 & -15 \\
MNGE & 22 & 20 & 20 & & 18 & 18 & 18 \\
\hline
\end{tabular}

criterion of $\pm 15 \%$, the MNGE is always largely under the criterion of $30 \%$. For $\mathrm{PM}_{10}$, the model performance criterion is met for the three networks. Furthermore, the results obtained for EMEP and BDQA largely meet the model performance goal, with MFE and MFB well under the thresholds fixed by the goal. Although the criterion was designed for $\mathrm{PM}_{10}$ and $\mathrm{PM}_{2.5}$, the model performance criterion is met for all aerosol species except chloride. Fig. 5 shows the MFE at each of the EMEP stations for $\mathrm{PM}_{2.5}$, sulfate, nitrate and ammonium. For $\mathrm{PM}_{2.5}$, the model performance goal is met for only 4 stations out of 17 , and the model performance criterion is not met for only 4 stations. Better results are obtained for sulfate and ammonium. For sulfate, 38 stations meet the model performance goal, and only 5 stations out of 57 do not meet the model performance criterion. For ammonium, 7 stations out of 9 meet the model performance goal and only 2 stations out of 9 do not meet the model performance goal and criterion. For nitrate, the results are not as good as for sulfate and ammonium: only 2 stations meet the performance goal, and only 8 stations out of 14 meet the performance criterion. Most of the largest errors correspond to low nitrate concentrations $\left(\simeq 1 \mu \mathrm{g} \mathrm{m}^{-3}\right)$.

\subsubsection{Comparison to previous intercomparison}

For ozone, compared to TNO-04, the observed values reported in Table 1 cover a large range. Values as low as $50 \mu \mathrm{g} \mathrm{m}^{-3}$ for AirBase and as high as $63 \mu \mathrm{g} \mathrm{m}^{-3}$ for EMEP are reported. However, the RMSE obtained with Polyphemus are within the low range of those of TNO-04 (24.3-26.0 against 23.1-28.1), and the correlations are slightly higher

Table 2

Statistics obtained with Polyphemus over Europe in 2001 for gaseous species: number of stations used to compute the statistics, observed mean $\left(\mu \mathrm{g} \mathrm{m}^{-3}\right)$, modeled mean $\left(\mu \mathrm{g} \mathrm{m}^{-3}\right)$, RMSE $\left(\mu \mathrm{g} \mathrm{m}^{-3}\right)$, correlation $(\%)$, MFB $(\%)$, MFE $(\%)$

\begin{tabular}{|c|c|c|c|c|c|c|c|c|}
\hline & Database & Stations & Obs. mean & Mod. mean & RMSE & Corr. & MFB & MFE \\
\hline \multirow[t]{3}{*}{$\mathrm{NO}_{2}$} & EMEP & 20 & 10.0 & 12.3 & 10.1 & 33.6 & 14 & 70 \\
\hline & AirBase & 990 & 23.9 & 15.3 & 18.3 & 39.5 & -38 & 74 \\
\hline & BDQA & 84 & 21.9 & 13.8 & 18.2 & 38.2 & -47 & 70 \\
\hline \multirow[t]{2}{*}{$\mathrm{NH}_{3}$} & EMEP & 3 & 7.4 & 6.3 & 5.4 & 29.5 & 11 & 52 \\
\hline & AirBase & 9 & 12.9 & 7.4 & 12.9 & 28.4 & -21 & 92 \\
\hline $\mathrm{HNO}_{3}$ & EMEP & 7 & 0.7 & 1.3 & 1.4 & 26.5 & 36 & 89 \\
\hline \multirow[t]{3}{*}{$\mathrm{SO}_{2}$} & EMEP & 43 & 2.0 & 5.2 & 4.8 & 47.5 & 96 & 105 \\
\hline & AirBase & 956 & 6.4 & 6.9 & 6.5 & 44.5 & 22 & 70 \\
\hline & BDQA & 10 & 7.8 & 6.6 & 6.4 & 36.4 & -16 & 60 \\
\hline
\end{tabular}


Table 3

Statistics obtained with Polyphemus over Europe in 2001 for aerosols: number of stations used to compute the statistics, observed mean $\left(\mu \mathrm{g} \mathrm{m}^{-3}\right)$, modeled mean $\left(\mu \mathrm{g} \mathrm{m}^{-3}\right)$, RMSE $\left(\mu \mathrm{g} \mathrm{m}^{-3}\right)$, correlation $(\%)$, MFB $(\%)$, MFE $(\%)$

\begin{tabular}{|c|c|c|c|c|c|c|c|c|}
\hline & Database & Stations & Obs. mean & Mod. mean & RMSE & Corr. & MFB & MFE \\
\hline \multirow[t]{3}{*}{$\mathrm{PM}_{10}$} & EMEP & 26 & 16.9 & 15.6 & 12.6 & 54.5 & -7 & 50 \\
\hline & AirBase & 529 & 24.9 & 15.4 & 16.6 & 44.0 & -42 & 58 \\
\hline & BDQA & 23 & 19.8 & 15.8 & 9.6 & 57.0 & -25 & 40 \\
\hline $\mathrm{PM}_{2.5}$ & EMEP & 17 & 12.6 & 8.4 & 8.6 & 54.1 & -39 & 61 \\
\hline \multirow[t]{2}{*}{ Sulfate } & EMEP & 57 & 2.5 & 2.1 & 1.7 & 55.8 & -4 & 50 \\
\hline & AirBase & 11 & 1.9 & 2.4 & 1.6 & 51.3 & 41 & 65 \\
\hline \multirow[t]{2}{*}{ Nitrate } & EMEP & 14 & 2.6 & 4.1 & 3.1 & 41.4 & 32 & 75 \\
\hline & AirBase & 8 & 3.5 & 4.4 & 2.7 & 71.7 & 8 & 54 \\
\hline \multirow[t]{2}{*}{ Amm. } & EMEP & 9 & 1.8 & 2.0 & 1.3 & 51.9 & 20 & 50 \\
\hline & AirBase & 8 & 1.8 & 2.0 & 0.9 & 74.7 & 15 & 36 \\
\hline Sodium & EMEP & 3 & 1.3 & 3.1 & 3.0 & 62.8 & 67 & 79 \\
\hline Chloride & AirBase & 7 & 0.9 & 3.1 & 3.5 & 69.8 & 83 & 102 \\
\hline
\end{tabular}
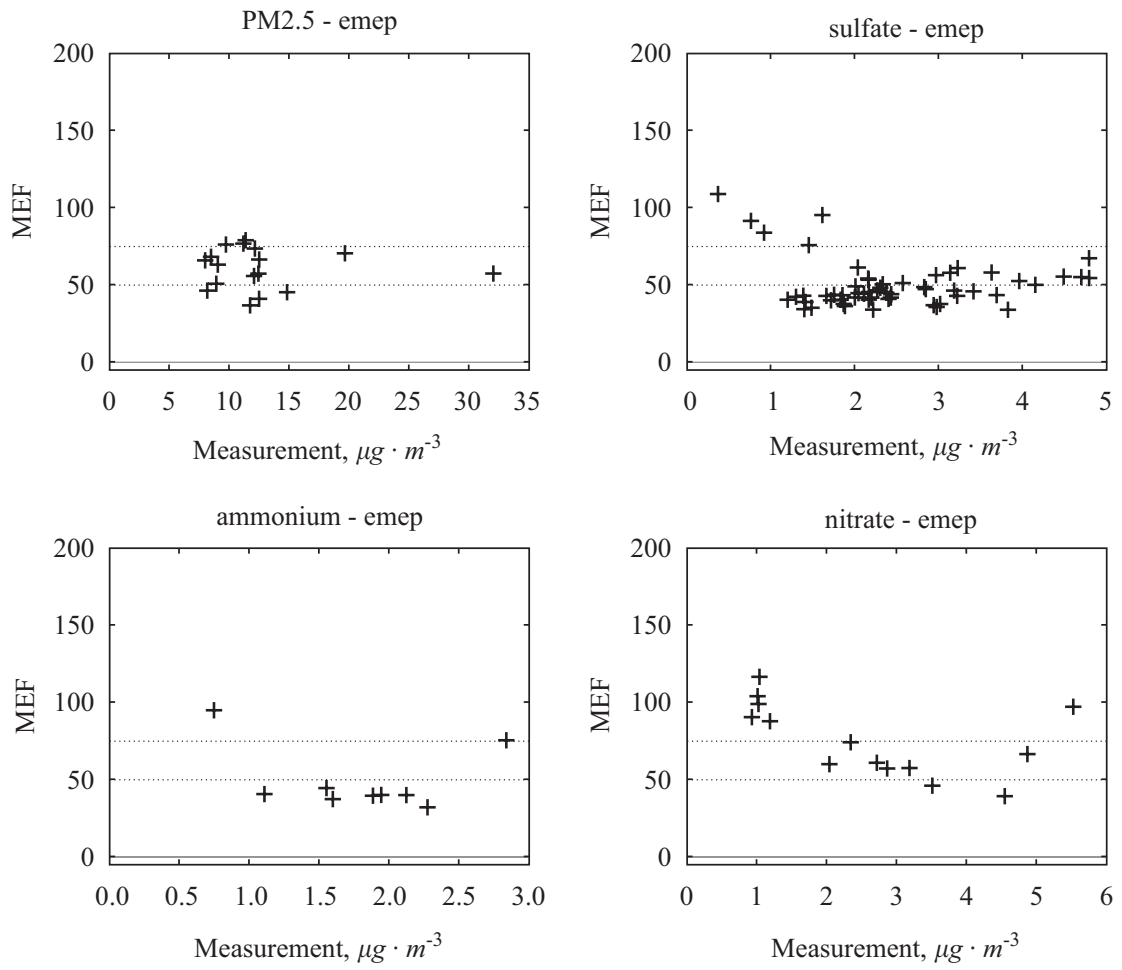

Fig. 5. MFE at each of the EMEP stations for $\mathrm{PM}_{2.5}$, sulfate, nitrate and ammonium. The dashed lines represent the model performance goal of $50 \%$ and the model performance criterion of $75 \%$.

(63.9-69.1\% against 54-59\%). This suggests that the results obtained with Polyphemus are comparatively good for hourly ozone. However, for ozone peaks, although the results are good, RMSE obtained with Polyphemus are in the high range
(21.4-23.5 against 18.1-22.1) and correlation in the low range (72.1-77.4\% against $73-83 \%$ ).

For $\mathrm{NO}_{2}$, observed values differ by a factor 2 depending on the network. Good results are observed for the EMEP database with RMSE as 
low as 10. However, Polyphemus has difficulties representing the high concentrations observed with AirBase or BDQA. These high concentrations may be explained by suburban stations that have not been filtered out. Note that these high concentrations are much higher than the observed mean of TNO-04 (18 against $15 \mu \mathrm{g} \mathrm{m}^{-3}$ ). Accordingly, the RMSE associated with these observations are high. However, correlations are in the same range as those of TNO-04 (33.6-39.5\% against 30-46\%).

For $\mathrm{SO}_{2}$, observed values differ by a factor 3 depending on the network. The low $\mathrm{SO}_{2}$ concentrations observed with the EMEP network are largely overestimated by Polyphemus (2.0 against 5.3). However, the higher concentrations observed with AirBase and BDQA are well represented. If the high concentrations in AirBase and BDQA are explained by suburban stations that are not filtered out, Polyphemus has a tendency to overestimate $\mathrm{SO}_{2}$ concentrations. The RMSE $\left(4.8-6.5 \mu \mathrm{g} \mathrm{m}^{-3}\right)$ are in the range of those of TNO-04, which spans from 3.2 to values as high as $10.1 \mu \mathrm{g} \mathrm{m}^{-3}$, but correlations lie in the low range (36.4-47.5\% against $39-49 \%$ ).

For $\mathrm{PM}_{10}$, the concentrations observed at EMEP stations are lower than those observed at AirBase and BDQA stations (16.9 against 24.9 and $19.8 \mu \mathrm{g} \mathrm{m}^{-3}$ ). Polyphemus does not reproduce these high concentrations. In TNO-04, all models tend to underestimate the $\mathrm{PM}_{10}$ concentrations. As the range of observed values is large and the observed values of TNO-04 are in the middle of this range, the range of RMSE predicted by POLYPHEMUS is also large (9.6-16.6 against $12.4-15.2 \mu \mathrm{g} \mathrm{m}^{-3}$ ). However, the correlations obtained with Polyphemus are in the high range of those of TNO-04 (44-57\% against $38-55 \%$ ).

For sulfate, the concentrations observed with AirBase are slightly lower than the lower observed concentrations of TNO-04 (1.9 against $2.3 \mu \mathrm{g} \mathrm{m}^{-3}$ ). The RMSE obtained with POLYPHEMus are slightly lower $\left(1.6-1.7 \mu \mathrm{g} \mathrm{m}^{-3}\right.$ against $1.8-2.9 \mu \mathrm{g} \mathrm{m}^{-3}$ ), while correlations are in the range of TNO-04 (50-65\% against $50-62 \%$ ).

For ammonium, the observed values as well as the modeled mean and the RMSE are in the range of TNO-04. The correlations obtained with POLYPHEMUS with AirBase are higher (51.9-74\% against 44-56\%).

For nitrate, the modeled concentrations (4.1-4.4 $\mu \mathrm{g} \mathrm{m}^{-3}$ ) are higher than those of TNO-04 $\left(1.5-2.9 \mu \mathrm{g} \mathrm{m}^{-3}\right)$. The RMSE tends to be slightly higher with Polyphemus $\left(2.7-3.1 \mu \mathrm{g} \mathrm{m}^{-3}\right.$ against a maximum of 2.7 in TNO-04). Correlations are, however, much better with Polyphemus (54-75\% against a maximum of 46 in TNO-04).

Although good comparisons of $\mathrm{NH}_{3}$ concentrations are obtained with the EMEP network, the high $\mathrm{NH}_{3}$ concentrations $\left(12.9 \mu \mathrm{g} \mathrm{m}^{-3}\right)$ observed with AirBase are not reproduced by Polyphemus $\left(7.4 \mu \mathrm{g} \mathrm{m}^{-3}\right)$. $\mathrm{HNO}_{3}$ concentrations are largely overestimated compared to the EMEP network $(0.7$ against $1.3 \mu \mathrm{g} \mathrm{m}^{-3}$ ).

Polyphemus overpredicts sodium and chloride, especially chloride, even though good correlations with measurements are obtained $(63 \%$ and $70 \%)$. This seems to indicate that the intensity of sea-salt emissions is high. However, the results are very localized: the three stations for sodium are in Denmark and the seven stations for chloride in The Netherlands.

\subsubsection{Variability}

To illustrate the spatial and temporal variability of the pollutant concentrations, model results versus measurements are plotted at the different EMEP stations for hourly concentrations for $\mathrm{O}_{3}$ and $\mathrm{NO}_{2}$ (Fig. 6), and for daily concentrations for $\mathrm{PM}_{10}$, sulfate, ammonium and nitrate (Fig. 7). Very good results are obtained for ozone, with as much as $93.3 \%$ of model results that fall within a factor 2 of measurements, and $99.6 \%$ that fall within a factor 5 . For $\mathrm{NO}_{2}$, only $50.3 \%$ of model results fall within a factor 2 of measurements, but $88.3 \%$ fall within a factor 5. For PM, 70.6\%, 71.6\% and $73.3 \%$ of model results fall within a factor 2 of measurements for $\mathrm{PM}_{10}$, sulfate and ammonium, respectively, and $97.5 \%, 96.5 \%$ and $94.6 \%$ fall within a factor 5 . Larger discrepancies are observed for nitrate with $50.8 \%$ of model results that fall within a factor 2 of measurements, and $82.1 \%$ within a factor 5 .

\subsection{Monthly variations}

The monthly variations of measured and simulated daily concentrations at the EMEP stations are plotted in Figs. 8 and 9. The results strongly vary with the season. In general, results tend to be better in summer than in winter.

For ozone, best results are observed between April and August when the concentrations are the highest. 

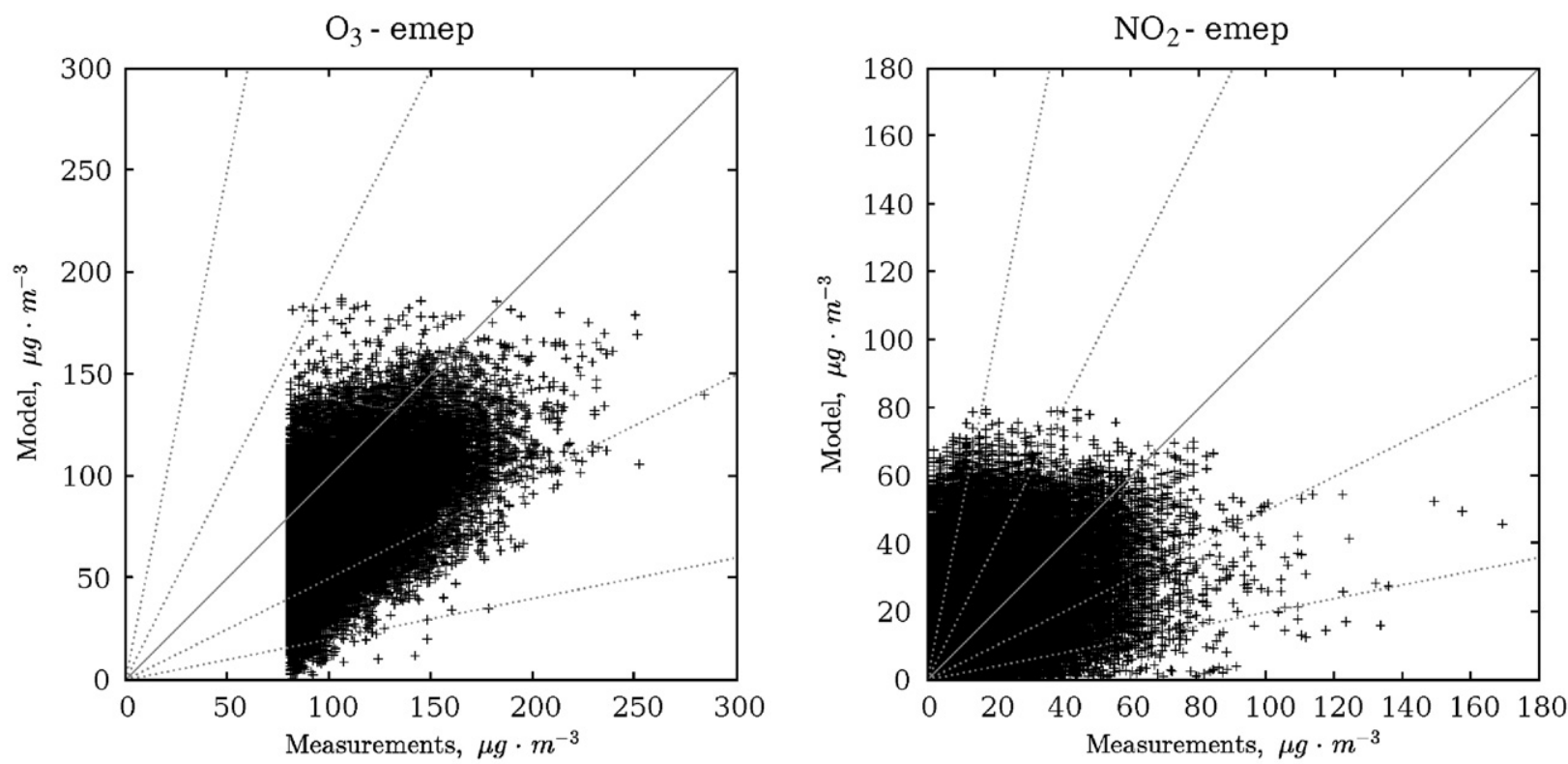

Fig. 6. Model results versus measurements for hourly concentrations at different EMEP stations for $\mathrm{O}_{3}$ and $\mathrm{NO}_{2}$. 1:1, 1:2, 2:1, 1:5 and 5:1 reference lines are provided.
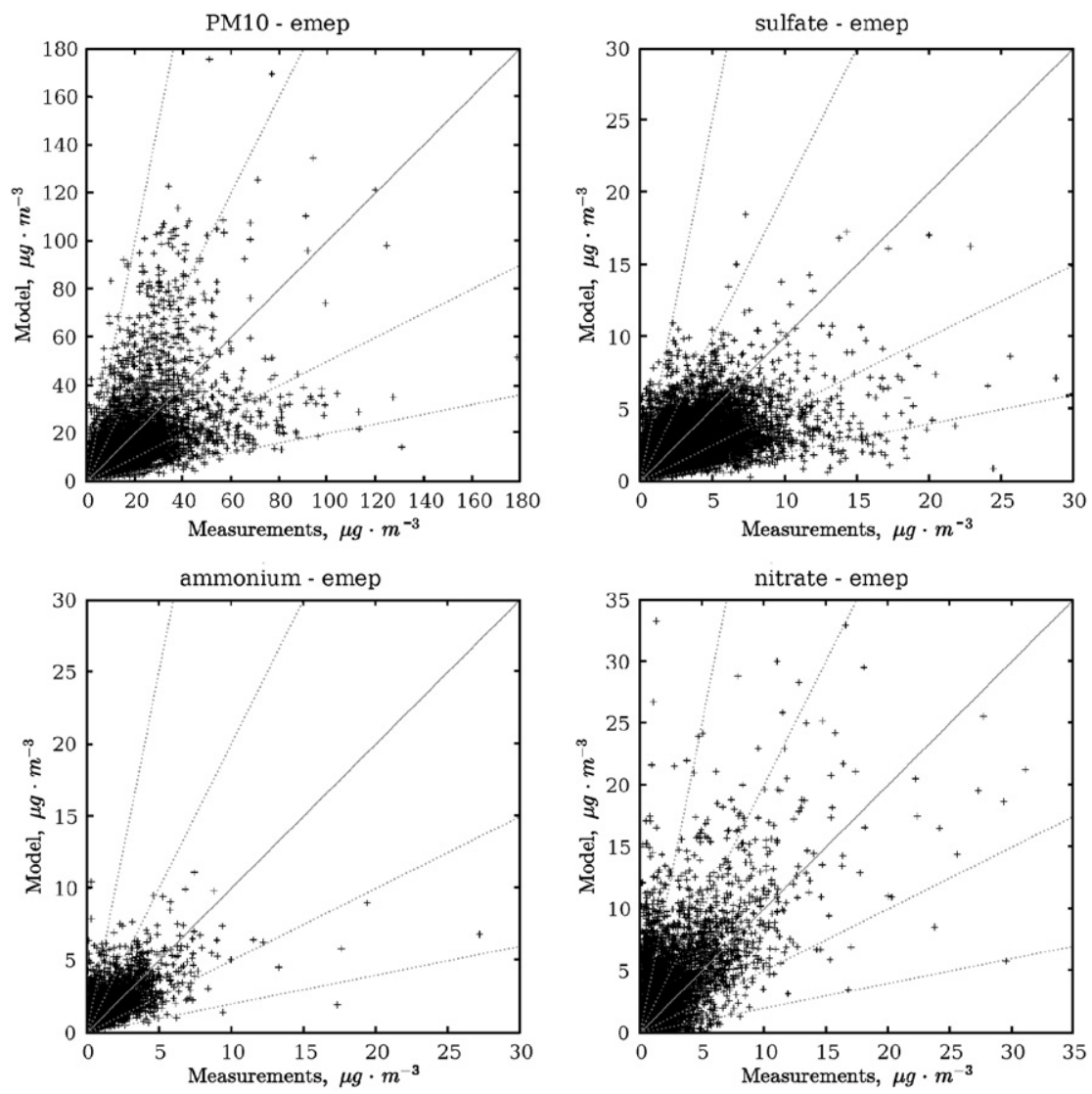

Fig. 7. Model results versus measurements for daily concentrations at different EMEP stations for PM 10 , sulfate, ammonium and nitrate. $1: 1,1: 2,2: 1,1: 5$ and 5:1 reference lines are provided. 

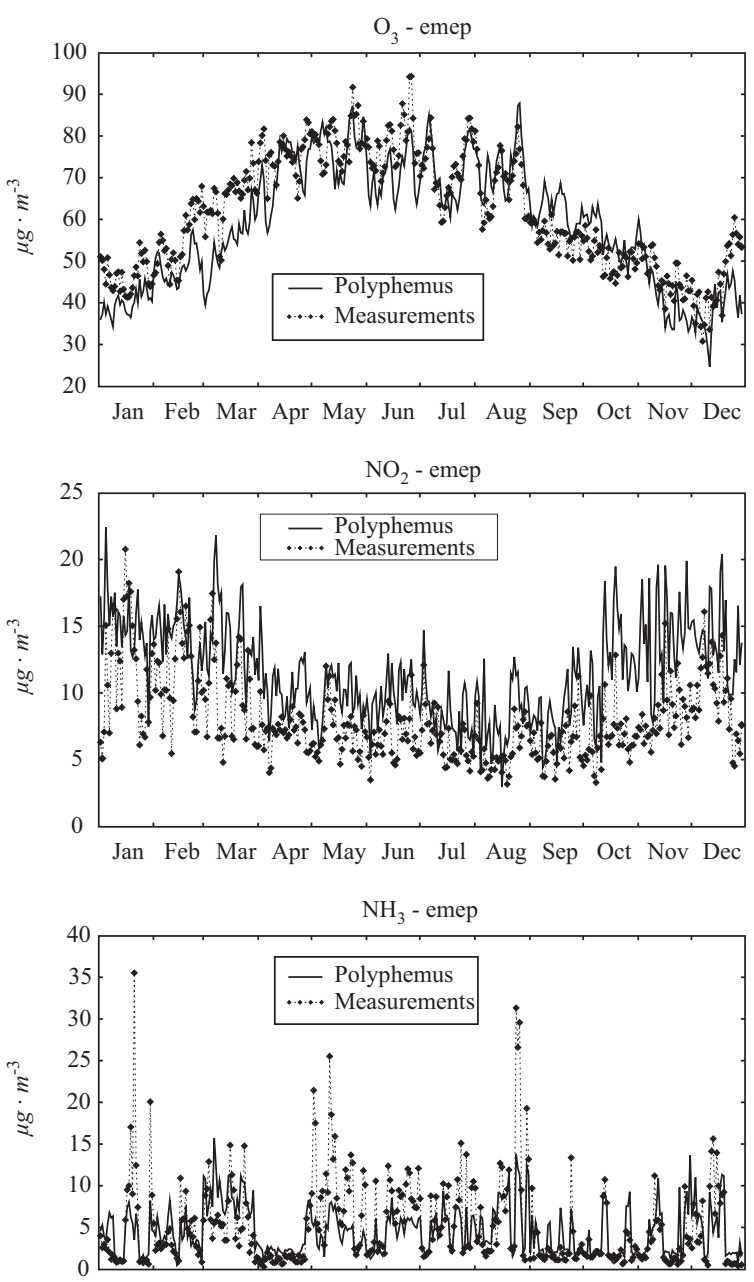

Jan Feb Mar Apr May Jun Jul Aug Sep Oct Nov Dec

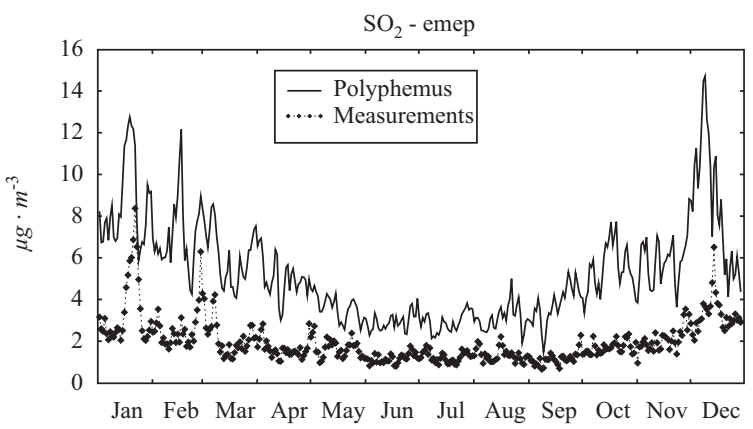

Fig. 8. Time series of daily concentrations of $\mathrm{O}_{3}, \mathrm{NO}_{2}, \mathrm{NH}_{3}$ and $\mathrm{SO}_{2}$ at the EMEP stations.

The concentrations of $\mathrm{NO}_{2}$ tend to be overestimated all through the year, especially during the winter months. Although $\mathrm{NO}_{2}$ is overestimated at the EMEP stations, it is underestimated at the AirBase and BDQA stations.
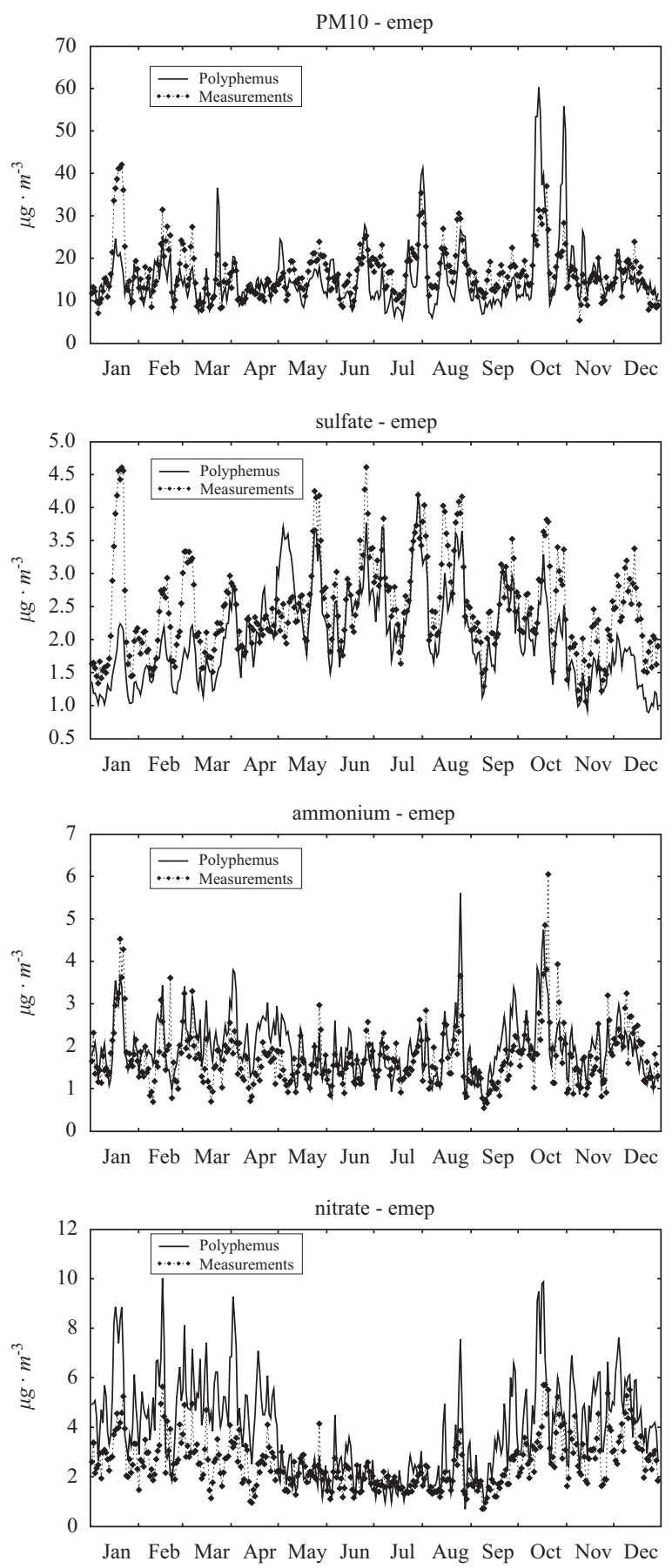

Fig. 9. Time series of daily concentrations of sulfate, ammonium and nitrate at the EMEP stations.

$\mathrm{NH}_{3}$ tends to be underestimated in summer.

For $\mathrm{SO}_{2}$, best results are obtained between May and August, when $\mathrm{SO}_{2}$ is not as strongly overestimated as the rest of the year. As for $\mathrm{NO}_{2}$, the overestimation of $\mathrm{SO}_{2}$ is not so large at the AirBase 
or the BDQA stations compared to the EMEP stations.

$\mathrm{PM}_{10}$ tends to be underestimated, except between October and December, where it is slightly overestimated. The underestimation of $\mathrm{PM}_{10}$ is larger when looking at the AirBase or the BDQA databases. The underestimation of $\mathrm{PM}_{10}$ during the summer months may be explained by the underestimation of secondary organic aerosols. At the EMEP stations, the simulated primary and secondary organic aerosols represent only about $6 \%$ of the total aerosol mass, whereas Putaud et al. (2004) estimates the percentage of organics between 16 to $22 \%$. Polyphemus does not take into account all precursors such as isoprene (Henze and Seinfeld, 2006) and sesquiterpenes (Pun et al., 2006a). Some processes such as the oligomerization in the particulate phase, the formation of organics in the aqueous phase (Pun et al., 2006b), the formation of organosulfates (Surratt et al., 2007) and organonitrates are not considered. Another reason of the underestimation of $\mathrm{PM}_{10}$ may lie in Saharan dust episodes, which may contribute to daily $\mathrm{PM}_{10}$ levels by as much as $20 \mu \mathrm{g} \mathrm{m}^{-3}$ (Gobbi et al., 2007). Saharan dust episodes are neglected in the simulations and the GOCART boundary conditions for dust are divided by a factor 4 . However, at the EMEP stations, the simulated dust represents about $25 \%$ of the total aerosol mass, whereas Putaud et al. (2004) estimates the percentage of dust between $9 \%$ and $19 \%$. The dust episodes could influence nitrate concentrations. The heterogeneous formation of nitrate on dust particles (e.g. Dentener et al., 1996; Hodzic et al., 2006ba) tends to decrease the $\mathrm{HNO}_{3}$ concentrations and to increase nitrate concentrations of coarse aerosols in summer.

For sulfate, results tend to be better between June and August. Although $\mathrm{SO}_{2}$ is strongly overestimated throughout the year in the EMEP database, sulfate is underestimated, especially between October and March. As emphasized by Bessagnet et al. (2004), sulfur aqueous chemistry, which is predominant in winter, is very difficult to simulate, because it is very sensitive to $\mathrm{pH}$. The strong overprediction of nitrate in winter may be explained by the underprediction of sulfate. Because sulfate is underpredicted, more nitrate is required to neutralize ammonium.

For ammonium, the seasonality is not as clear as for other pollutants. It has a slight tendency to be overpredicted in spring. Although $\mathrm{NH}_{3}$ tends to be underestimated in summer, good results are obtained for ammonium.

\subsection{Discussion}

The results obtained with Polyphemus for a 1-year simulation over Europe are good. Model performance criteria are met for ozone and particulate species like $\mathrm{PM}_{10}$, sulfate, nitrate, and ammonium. Comparisons of correlations and RMSE with those of other models run over Europe for 2001 point out the strengths and limitations of Polyphemus.

Good results are obtained with Polyphemus for hourly ozone, sulfate and ammonium. Correlations tend to be in the high range for different pollutants such as $\mathrm{PM}_{10}$, sulfate, ammonium, nitrate and even chloride and sodium. However, $\mathrm{SO}_{2}$ and nitrate concentrations tend to be overestimated.

The robustness of the results obtained with Polyphemus, as an example of CTM, may be questioned. The system is likely sensitive to different parameterizations, inputs, and numerics. Each parameterization or input is likely to influence the pollutants differently in winter and summer. For example, parameterizations related to the aqueous module are more likely to impact aerosol concentrations in winter. On top of differences in ambient conditions, a sensitivity study on modifications of the system configuration and parameterizations may allow us to understand which processes cause pollutants to be overestimated or underestimated, which, as shown above, often depends on the season.

On top of questioning the robustness of the modeling system, one may question the robustness of model-to-data error statistics. Large differences exist between the EMEP and the AirBase measurements, although both databases cover Europe (Fig. 1). For example, the observed mean for $\mathrm{O}_{3}$ and $\mathrm{NO}_{2}$ are 63.2 and $10.0 \mu \mathrm{g} \mathrm{m}^{-3}$, respectively, with EMEP and 49.9 and $23.9 \mu \mathrm{g} \mathrm{m}^{-3}$, respectively, with AirBase. The observed mean for $\mathrm{PM}_{10}$ is $16.9 \mu \mathrm{g} \mathrm{m}^{-3}$ with EMEP and $24.9 \mu \mathrm{g} \mathrm{m}^{-3}$ with AirBase. These differences may not only be caused by the observational error due to artifacts in measurement methods but also by the way the stations are filtered in the database. For example, some sites may not be truly representative of background values, and some sites may be strongly impacted by local conditions, such as orography. This difficulty in comparing different database measurements is 
reflected in the error statistics, which differ depending on the database used. For $\mathrm{PM}_{10}$, the RMSE is only $12.6 \mu \mathrm{g} \mathrm{m}^{-3}$ for EMEP, but becomes as high as $16.6 \mu \mathrm{g} \mathrm{m}^{-3}$ for AirBase.

\section{Conclusion and future work}

The Polyphemus system has been extended to aerosol modeling by hosting the SIREAM model. The simulation of 2001 over Europe has been studied through an extensive model-to-data comparison for three observational networks (EMEP, AirBase and BDQA). The results, while variable between the chemical species, are good given the results of other such models. The limitations of the model have been pointed out. For example, a more detailed treatment of the formation of secondary organic aerosols is required.

Apart from the conclusions related to the performance of the modeling system, one may question the robustness of such models. A comprehensive sensitivity analysis is required and is the subject of a further paper that investigates the sensitivity of model results with respect to many modeling inputs (physical parameterizations, numerics). Moreover, the error statistics may significantly differ from one network to another, which underlines the difficulty of having fair and robust model-to-data error statistics.

\section{Acknowledgements}

Part of this project has been funded by the French Research Program, Primequal-Predit, in the framework of the PAM Project (Multiphase Air Pollution). Some of the authors (K. Fahey, K. Sartelet and $\mathrm{M}$. Tombette) have been partially funded by the Region Ile de France.

We thank Spyros Pandis (Carnegie Mellon University and the University of Patras) for his help in aerosol modeling. We also thank our colleague Hadjira Foudhil for her help in the development of Polair3D. We thank our colleagues Vivien Mallet and Denis Quélo for having helped to adapt the Polyphemus system for aerosol modeling. We thank Christian Seigneur for discussions about the composition of $\mathrm{PM}_{10}$.

\section{Appendix A. Statistical indicators}

The following indicators are computed by the AтмоPy module in order to evaluate error statistics for model-to-data comparisons. Let $\left(o_{i}\right)_{i}$ and $\left(c_{i}\right)_{i}$ be the observed and the modeled concentrations at time and location $i$, respectively. Let $n$ be the number of data.

We define the following indicators:

- Root mean square error (RMSE):

$$
\sqrt{\frac{1}{n} \sum_{i=1}^{n}\left(c_{i}-o_{i}\right)^{2}} \text {. }
$$

- Correlation:

$$
\begin{aligned}
& \frac{\sum_{i=1}^{n}\left(c_{i}-\bar{c}\right)\left(o_{i}-\bar{o}\right)}{\sqrt{\sum_{i=1}^{n}\left(c_{i}-\bar{c}\right)^{2}} \sqrt{\sum_{i=1}^{n}\left(o_{i}-\bar{o}\right)^{2}}} \\
& \text { with: } \bar{o}=\frac{1}{n} \sum_{i=1}^{n} o_{i} \quad \text { and } \quad \bar{c}=\frac{1}{n} \sum_{i=1}^{n} c_{i} .
\end{aligned}
$$

- Mean normalized bias error (MNBE):

$$
\frac{1}{n} \sum_{i=1}^{n} \frac{c_{i}-o_{i}}{o_{i}}
$$

- Mean normalized gross error (MNGE):

$\frac{1}{n} \sum_{i=1}^{n} \frac{\left|c_{i}-o_{i}\right|}{o_{i}}$

- Mean fractional bias (MFB):

$\frac{1}{n} \sum_{i=1}^{n} \frac{c_{i}-o_{i}}{\left(c_{i}+o_{i}\right) / 2}$

- Mean fractional error (MFE):

$$
\frac{1}{n} \sum_{i=1}^{n} \frac{\left|c_{i}-o_{i}\right|}{\left(c_{i}+o_{i}\right) / 2} \text {. }
$$

\section{References}

Ackermann, I., Hass, H., Memmsheimer, M., Ziegenbein, C., Ebel, A., 1995. The parameterization of the sulfate-nitrate-ammonia aerosol system in EURAD. Meteorology and Atmospheric Physics 57, 101-114.

Bessagnet, B., Hodzic, A., Vautard, R., Beekmann, M., Cheinet, S., Honore, C., Liousse, C., Rouil, L., 2004. Aerosol modeling with CHIMERE - preliminary evaluation at the continental scale. Atmospheric Environment 38, 2803-2817.

Boylan, J., Russell, A., 2006. PM and light extinction model performance metrics, goals, and criteria for three-dimensional 
air quality models. Atmospheric Environment 40 (26), 4946-4959.

Brandt, J., 1998. Modelling transport, dispersion and deposition of passive tracers from accidental releases. Ph.D. Thesis, NERI, Denmark.

Chin, M., Rood, R., Lin, S.-J., Muller, J., Thomspon, A., 2000. Atmospheric sulfur cycle in the global model GOCART: model description and global properties. Journal of Geophysical Research 105, 24,671-24,687.

Cousin, F., Liousse, C., Cachier, H., Bessagnet, B., Guillaume, B., Rosset, R., 2005. Aerosol modelling and validation during ESCOMPTE 2001. Atmospheric Environment 39, 1539-1550.

Debry, E., Fahey, K., Sartelet, K., Sportisse, B., Tombette, M., 2007. Technical note: a new size REsolved Aerosol Model: SIREAM. Atmospheric Chemistry and Physics Discussions 7, 1537-1547.

de Meij, A., Krol, M., Dentener, F., Vignati, E., Cuvelier, C., Thunis, P., 2006. The sensitivity of aerosol in Europe to two different emission inventories and temporal distribution of emissions. Atmospheric Chemistry and Physics Discussions 6, 4287-4309.

Dentener, F., Carmichael, G., Zhang, Y., Lelieveld, J., Crutzen, P., 1996. Role of mineral aerosol as a reactive surface in the global troposphere. Journal of Geophysical Research 101, 22,869-22,889.

EPA, 1991. Guideline for regulatory application of the urban airshed model. Technical Report, EPA, technical report.

GENEMIS, 1994. GENEMIS (generation and evaluation of emission) data. Technical Report, EUROTRAC, annual report 1993.

Gerber, H., 1985. Relative-humidity parameterization of the Navy aerosol model (NAM). Technical Report 8956, National Research Laboratory, Washington, DC.

Gobbi, G.P., Barnaba, F., Ammannato, L., 2007. Estimating the impact of Saharan dust on the year 2001 PM10 record of Rome, Italy. Atmospheric Environment 41, 261-275.

Haywood, J., Boucher, O., 2000. Estimates of the direct and indirect radiative forcing due to tropospheric aerosols. Reviews of Geophysics 38, 513-543.

Henze, D., Seinfeld, J., 2006. Global secondary organic aerosol from isoprene oxidation. Geophysical Research Letters 33, L09812.

Hodzic, A., Bessagnet, B., Vautard, R., 2006a. A model evaluation of coarsemode nitrate heterogeneous formation on dust particles. Atmospheric Environment 40, 4158-4171.

Hodzic, A., Vautard, R., Chepfer, H., Goloub, P., Menut, L., Chazette, P., Deuze, J., Apituley, A., Couvert, P., 2006b. Evolution of aerosol optical thickness over Europe during the August 2003 heat wave as seen from CHIMERE model simulations and POLDER data. Atmospheric Chemistry and Physics Discussions 6, 1853-1864.

Hoek, G., Brunekreef, B., Goldbohm, S., Fisher, P., van den Brandt, P., 2002. Association between mortality and indicators of traffic-related air pollution in The Netherlands: a cohort study. The Lancet 360, 1203-1209.

Johnson, D., Utembe, S., Jenkin, M., Derwent, R., Hayman, G., Alfarra, M., Coe, H., McFiggans, G., 2006. Simulating regional scale secondary organic aerosol formation during the TORCH 2003 campaign in the southern UK. Atmospheric Chemistry and Physics Discussions 6, 403-418.

Loosmore, G., Cederwall, R., 2004. Precipitation scavenging of atmospheric aerosols for emergency response applications: testing an updated model with new real-time data. Atmospheric Environment 38, 993-1003.

Loubet, B., Cellier, P., Genermont, S., Laville, P., Flura, D., 2003. Measurement of short-range dispersion and deposition of ammonia over a maize canopy. Agricultural and Forest Meteorology 114, 175-196.

Louis, J., 1979. A parametric model of vertical eddy fluxes in the atmosphere. Boundary-Layer Meteorology 17, 197-202.

Mallet, V., Sportisse, B., 2005. A comprehensive study of ozone sensitivity with respect to emissions over Europe with a chemistry-transport model. Journal of Geophysical Research 110 (D22).

Mallet, V., Sportisse, B., 2006a. Ensemble-based air quality forecasts: a multimodel approach applied to ozone. Journal of Geophysical Research 111, D18302.

Mallet, V., Sportisse, B., 2006b. Uncertainty in a chemistrytransport model due to physical parameterizations and numerical approximations: an ensemble approach applied to ozone modeling. Journal of Geophysical Research 111, D01302.

Middleton, P., Stockwell, W., Carter, W., 1990. Aggregation and analysis of VOC emissions for regional modelling. Atmospheric Environment 24, 1107-1133.

Monahan, E., Spiel, D., Davidson, K., 1986. A model of marine aerosol generation via whitecaps and wave disruption. In: Oceanic Whitecaps. D. Reidel, Dordrecht, pp. 167-174.

Pandis, S., Seinfeld, J., Pilinis, C., 1990. The smog-fog-smog cycle and acid deposition. Journal of Geophysical Research 95, 18,489-18,500.

Park, R., Jacob, D., Field, B., Yantosca, R., 2004. Natural and trans-boundary pollution influences on sulfate-nitrate-ammonium aerosols in the United States: implications for policy. Journal of Geophysical Research 109, D15204.

Passant, N., 2002. Speciation of UK emissions of NMVOC. AEA Technology, AEAT/ENV/0545.

Pope, C., Thun, M., Namboodiri, M., Dockery, D., Evans, J., Speizer, F., Heath, C., 1995. Particulate air pollution as a predictor of mortality in a prospective study of US adults. American Journal of Respiratory and Critical Care Medicine 151, 669-674.

Pun, B., Seigneur, C., Lohman, K., 2006a. Modeling secondary organic aerosol formation via multiphase partitioning with molecular data. Environmental Science and Technology 40, $4722-4731$.

Pun, B., Seigneur, C., Lohman, K., 2006b. Oligomer formation in evaporating aqueous glyoxal and methyl glyoxal solutions. Environmental Science and Technology 40, 6318-6323.

Putaud, J., Dingenen, R., Baltensperger, U., Brggemann, E., Charron, A., Facchini, M., Decesari, S., Fuzzi, S., Gehrig, R., Hansson, H., Harrison, R., Jones, A., Laj, P., Lorbeer, G. Maenhaut, W., Mihalopoulos, N., Mller, K., Palmgren, F., Querol, X., Rodriguez, S., Schneider, J., Spindler, G., Brink, H., Tunved, P., Torseth, K., Weingartner, E., Wiedensohler, A., Wahlin, P., Raes, F., 2003. A European aerosol phenomenology. Technical Report, Joint Research Centre, Institute for Environment and Sustainability.

Putaud, J.-P., Raes, F., Van Dingenen, R., Bruggemann, E., Facchini, M.-C., Decesari, S., Fuzzi, S., Gehrig, R., Huglin, C., Laj, P., Lorbeer, G., Maenhaut, W., Mihalopoulos, N., Muller, K., Querol, X., Rodriguez, S., Schneider, J., Spindler, G., ten Brink, H., Torseth, K., Wiedensohler, A., 2004. A European aerosol phenomenology -2 : chemical characteris- 
tics of particulate matter at kerbside urban, rural and background sites in Europe. Atmospheric Environment 38, 2579-2595.

Quélo, D., Krysta, M., Bocquet, M., Isnard, O., Minier, Y., Sportisse, B., 2007. Validation of the Polyphemus system: the ETEX, Chernobyl and Algeciras cases. Atmospheric Environment, in press, doi:10.1016/j.atmosenv.2007.02.035.

Roselle, S., Binkowski, F., 1999. Cloud dynamics and chemistry. Technical Report, U.S. Environmental Protection Agency, EPA/600/R-99/030 (Chapter 11).

Roselle, S., Schere, K., Pleim, J., 1999. Photolysis rates for CMAQ. Technical Report, U.S. Environmental Protection Agency, EPA/600/R-99/030 (Chapter 14).

Roustan, Y., Bocquet, M., 2006. Sensitivity analysis for mercury over Europe. Journal of Geophysical Research 111, D14304.

Russell, A., Dennis, R., 2000. NARSTO critical review of photochemical models and modeling. Atmospheric Environment 34, 2283-2324.

Sartelet, K., Hayami, H., Sportisse, B., 2007. MICS-Asia Phase II: sensitivity to the aerosol module. Atmospheric Environment, in press, doi:10.1016/j.atmosenv.2007.03.005.

Sartelet, K.N., Hayami, H., Albriet, B., Sportisse, B., 2005. Development and preliminary validation of a modal aerosol model for tropospheric chemistry: MAM. Aerosol Science and Technology 40 (2), 118-127.

Schaap, M., 2003. On the importance of aerosol nitrate over Europe. Data analysis and modelling. Ph.D. Thesis, University of Utrecht, The Netherlands.

Schaap, M., Van Der Gon, H., Dentener, F., Visschedijk, A., Van Loon, M., ten Brink, H., Putaud, J.-P., Guillaume, B., Liousse, C., Builtjes, P., 2004a. Anthropogenic black carbon and fine aerosol distribution over Europe. Journal of Geophysical Research 109, D18207.

Schaap, M., Van Loon, M., ten Brink, H., Dentener, F., Builtjes, P., 2004b. Secondary inorganic aerosol simulations for Europe with special attention to nitrate. Atmospheric Chemistry and Physics Discussions 4, 857-874.

Schmidt, H., Derognat, C., Vautard, R., Beekmann, M., 2001. A comparison of simulated and observed ozone mixing ratios for the summer of 1998 in Western Europe. Atmospheric Environment 35, 6277-6297.

Seinfeld, J., Pandis, S., 1998. Atmospheric Chemistry and Physics. Wiley-Interscience, New York.

Simpson, D., Winiwarter, W., Brjesson, G., Cinderby, S., Ferreiro, A., Guenther, A., Hewitt, C., Janson, R., Khalil, M., Owen, S., Pierce, T., Puxbaum, H., Shearer, M., Skiba, U., Steinbrecher, R., Tarrason, L., Oquist, M., 1999. Inventorying emissions from nature in Europe. Journal of Geophysical Research 104 (D7), 8113-8152.

Simpson, D., Fagerli, H., Jonson, J.E., Tsyro, S., Wind, P., Tuovinen, J.-P., 2003. Transboundary acidification, euthrophication and ground level ozone in Europe. Part I: unified EMEP model description. Technical Report, EMEP.

Sportisse, B., Dubois, L., 2002. Numerical and theoretical investigation of a simplified model for the parameterization of below-cloud scavenging by falling raindrops. Atmospheric Environment 36, 5719-5727.
Sportisse, B., Sartelet, K., Debry, E., Fahey, K., Roustan, Y., Tombette, M., 2006. PAM project (multiphase air pollution): description of the aerosol models SIREAM and MAM. Technical Report 2006-08, CEREA. Available from: 〈http:// www.enpc.fr/cerea/polyphemus〉.

Stockwell, W., Kirchner, F., Kuhn, M., Seefeld, S., 1997. A new mechanism for regional atmospheric chemistry modeling. Journal of Geophysical Research 95 (D10), 16,343-16,367.

Surratt, J., Kroll, J., Kleindienst, T., Edney, E., Claeys, M., Sorooshian, A., Ng, N., Offenberg, J., Lewandowski, M., Jaoui, M., Flagan, R., Seinfeld, J., 2007. Evidence of organosulfates in secondary organic aerosol. Environmental Science and Technology 41, 517-527.

Torseth, K., Hov, O., 2003. The EMEP monitoring strategy 2004-2009. Technical Report, EMEP/CCC, 9/2003.

Troen, I.B., Mahrt, L., 1986. A simple model of the atmospheric boundary layer; sensitivity to surface evaporation. BoundaryLayer Meteorology 37, 129-148.

Tsyro, S., 2001. Description of the Lagrangian Acid Deposition Model. Technical Report, EMEP.

van Loon, M., Roemer, M., Builtjes, P., 2004. Model intercomparison in the framework of the review of the unified EMEP model. Technical Report, TNO Environment Energy and Process Innovation, R2004/282.

van Loon, M., Vautard, R., Schaap, M., Bergstrom, R., Bessagnet, B., Brandt, J., Builtjes, P., Christensen, J., Cuvelier, C., Graff, A., Jonson, J., Krol, M., Langner, J., Roberts, P., Rouil, L., Stern, R., Tarrasón, L., Thunis, P., Vignati, E., White, L., Wind, P., 2007. Evaluation of long-terme ozone simulations from seven air quality models and their ensemble. Atmospheric Environment 41, 2083-2097.

Vautard, R., Bessagnet, B., Chin, M., Menu, L., 2005. On the contribution of natural Aeolian sources to particulate matter concentrations in Europe: testing hypotheses with a modelling approach. Atmospheric Environment 39, 3291-3303.

Vautard, R., Builtjes, P., Thunis, P., Cuvelier, C., Bedogni, M., Bessagnet, B., Honoré, C., Moussiopoulos, N., Pirovano, G., Schaap, M., Stern, R., Tarrason, L., Wind, P., 2007. Evaluation and intercomparison of ozone and PM10 simulations by several chemistry transport models over four European cities within the Citydelta project. Atmospheric Environment 41, 173-188.

Wesely, M., 1989. Parameterization of surface resistance to gaseous-dry deposition in regional scale numerical models. Atmospheric Environment 23, 1293-1304.

Zhang, L., Gong, S., Padro, J., Barrie, L., 2001. A size-segregated particle dry deposition scheme for an atmospheric aerosol module. Atmospheric Environment 549-560.

Zhang, L., Brook, J., Vet, R., 2003. A revised parameterization for gaseous dry deposition in air-quality models. Atmospheric Chemistry and Physics Discussions 3, 2067-2082.

Zhang, Y., Liu, P., Queen, A., Misenis, C., Pun, B., Seigneur, C., Wu, S., 2006. A comprehensive performance evaluation of MM5-CMAQ for the Summer 1999 Southern Oxidants Study episode-part II: gas and aerosol predictions. Atmospheric Environment 40, 4839-4855. 